\title{
Perfil do conhecimento de estudantes do ensino médio de uma escola pública no norte do Tocantins sobre a associação da infecção pelo vírus HPV e a neoplasia de colo uterino
}

\section{Knowledge profile of students in high school in northern Tocantins about the association of infection by HPV virus and uterus colo neoplasia}

Daiene Isabel da Silva Lopes ${ }^{1 ;}$ Andressa Borges Brito2; José Fernando e Silva Pereira ${ }^{3}$; Thairine Marinho de Azevedo ${ }^{4}$; lara Brito Bucar Oliveira ${ }^{5}$

\section{RESUMO}

O presente trabalho tem como objetivo analisar o nível de conhecimento sobre a associação da infecção pelo vírus HPV e a neoplasia de colo do útero em estudantes do ensino médio. Assim, foi realizado um estudo descritivo, de corte transversal, com amostra intencional de 50 estudantes de escola pública em 2018, sendo 25 mulheres (11 a 14 anos) e 25 homens (11 a 14 anos). Os dados foram coletados através de questionários estruturados, apropriados ao sexo do entrevistado. Com os resultados obtidos, foi possível dimensionar o nível de conhecimento na amostra alvo da pesquisa sobre o conhecimento dos riscos da infecção pelo HPV como precursora de carcinoma ginecológico. $76 \%$ da amostra conhecia a relação (sendo $88 \%$ do sexo feminino e $12 \%$ do sexo masculino), $8 \%$ não e $16 \%$ não sabem. Também foi dimensionado na amostra se seriam vacinados contra o HPV, e posteriormente divididos por sexo. $28 \%$ do sexo masculino são vacinados, $40 \%$ não, e $32 \%$ não sabem. Já no sexo feminino $80 \%$ são vacinadas contra o HPV, $12 \%$ não são e $8 \%$ não sabem. Portanto, observou-se nas respostas que os entrevistados apresentam conhecimento superficial quando comparado as perspectivas do Ministério da Saúde a respeito da temática.

Palavras-chave: HPV. Neoplasia. Adolescentes. Prevenção. Vacinação.

\section{ABSTRACT}

The present work aims to analyze the level of knowledge about the association of HPV virus infection and cervical cancer in high school students. Thus, a descriptive, crosssectional study was carried out, with an intentional sample of 50 public school students in 2018 , being 25 women ( 11 to 14 years old) and 25 men (11 to 14 years old). The data were collected through structured questionnaires, appropriate to the interviewee's gender. With the results obtained, it was possible to measure the level of knowledge in the target sample of the research on the knowledge of the risks of HPV infection as a precursor of gynecological carcinoma. $76 \%$ of the sample knew the relationship (being $88 \%$ female and $12 \%$ male), $8 \%$ did not and $16 \%$ did not know. It was also dimensioned in the sample if they would be vaccinated against HPV, and later divided by sex. $28 \%$ of males are vaccinated, $40 \%$ are not, and $32 \%$ do not know. In women, $80 \%$ are vaccinated against HPV, $12 \%$ are not and $8 \%$ do not know. Therefore, it was observed in the responses that the interviewees present superficial knowledge when compared to the perspectives of the Ministry of Health regarding the theme.

Keywords: HPV. Neoplasm. Teens. Prevention. Vaccination.
1Doutora em Ciência Animal Tropical pela Universidade Federal do Tocantins (UFT). Docente no Centro Universitário Tocantinense Presidente Antônio Carlos (UNITPAC).

E-mail: daieneisabel@gmail.com https://orcid.org/0000-0002-2416-4961

2Graduanda em Medicina pelo Centro Universitário Tocantinense Presidente Antônio Carlos (UNITPAC). https://orcid.org/0000-0002-8419-8979

${ }^{3}$ Graduando em Medicina pelo Centro Universitário Tocantinense Presidente Universitário Tocantinense Presidente
Antônio Carlos (UNITPAC). https://orcid.org/0000-0002-4128-6338

${ }^{4}$ Graduanda em Medicina pelo Centro Universitário Tocantinense Presidente Universitario Tocantinense Presidente
Antônio Carlos (UNITPAC). https://orcid.org/0000-0003-4097-139X

${ }^{5}$ Mestre em Ciências ambientais e Saúde (PUC de Goiás). https://orcid.org/0000-0002-2335-988X 


\section{INTRODUCĀO}

Cerca de 13 tipos de HPV são considerados oncogênicos, e apresentam maior risco de provocar infecções persistentes e estar associados a lesões precursoras de câncer. Dentre os HPV de alto risco destacam-se os tipos 16 e 18 que estão presentes em 70\% dos casos de câncer do colo do útero. Aproximadamente 291 milhões de mulheres no mundo são portadoras do HPV, sendo que 32\% estão infectadas pelos tipos 16, 18 ou ambos e a incidência anual é de aproximadamente 500 mil casos de câncer de colo do útero (INCA,2015).

O vírus HPV pode infectar as células do epitélio basal da pele ou dos tecidos e são categorizados como cutâneos ou mucosos, indivíduos nos períodos de desenvolvimento caracterizados como infância e adolescência são mais susceptíveis a essas infecções. Os cutâneos são epidermotrópicos, infectam a pele das mãos e dos pés e se manifestam formando as verrugas. O tipo mucoso infecta o revestimento da boca, garganta, trato respiratório ou epitélio ano-genital e manifestam-se através de condilomas planos e acuminados (NAKAGAWA, SCHIRMER BARBIERI, 2010).

O câncer no colo do útero carrega um estigma de ser uma doença de regiões pobres. O carcinoma que mais afeta mulheres em países ou regiões ricas excluindo os casos de pele não melanoma é o câncer de mama já em países subdesenvolvidos da África, Ásia, América Central e do Sul é o carcinoma de colo de útero. Índices estes que se repetem no Brasil, onde o câncer de colo de útero já foi predominante em décadas passadas, mas houve inversão para o câncer de mama, no entanto, a incidência permanece alta nas regiões nordeste e norte sendo nesta última o tipo mais comum de câncer em mulheres com 23,97 casos por 100.000 mulheres (INCA, 2015).

O surgimento do câncer está relacionado à ocorrência de mutações genéticas nas células, que são alterações em seu DNA. Essas mutações acometem células normais e alteram seu ciclo celular, fazendo com que as células que sofreram mutação não recebam instruções para as suas atividades ou recebam instruções erradas. As células cancerosas violam as regras mais básicas de comportamento celular pelas quais os organismos multicelulares são construídos e mantidos, e exploram todos os tipos de oportunidade para fazê-lo (ALBERTS, 2017).

Com a vacinação contra o HPV antes do início da vida sexual e a realização de exame preventivo, que pode detectar as lesões precursoras é possível prevenir o câncer 
de colo do útero em $100 \%$ dos casos. O Ministério da Saúde, em 2014, iniciou a implementação da vacinação gratuita contra o HPV em meninas de 9 a 13 anos de idade, com a vacina quadrivalente, que engloba os tipos de HPV 6, 11, 16 e 18. Em 2017, as meninas de 14 anos também foram incluídas. Além disso, o esquema vacinal do SUS foi ampliado para meninos de 11 a 14 anos. Apesar das campanhas a cobertura vacinal fica aquém das expectativas do Ministério da Saúde. A vacinação nas meninas está em $46,2 \%$ para a segunda dose. Para os meninos o índice é ainda mais baixo: $20,2 \%$. A realidade está muito aquém da meta de 80\% (INCA, 2018).

Para o sucesso das campanhas de vacinação faz-se salutar o conhecimento das realidades regionais em saúde e para o esclarecimento de tais variáveis pesquisamos o percentual de cobertura vacinal contra o Papiloma vírus humano dentre a amostra analisada comparando os níveis de adesão à vacina entre os gêneros feminino e masculino. Também foi possível dimensionar na amostra alvo da pesquisa o nível de conhecimento sobre os riscos da infecção pelo HPV como precursora do Câncer de colo de útero.

\section{MATERIAIS E METODOS}

Este estudo foi desenvolvido pelo tipo descritivo, prospectivo do nível de conhecimento dos estudantes de uma escola pública sobre a associação do HPV com o Câncer de colo de útero. Foi escolhida uma escola de acordo com a disponibilidade da secretária de educação. Os possíveis participantes eram convidados a pesquisa de acordo com as salas previamente selecionadas pela direção da instituição de ensino. A coleta de dados foi feita por meio de questionários estruturados, apropriados ao sexo do entrevistado, aplicados no período de março a setembro de 2019. A amostra da pesquisa foi composta por 50 adolescentes estudantes, sendo 25 do sexo feminino (15 a 19 anos) e 25 do sexo masculino (15 a 19 anos).

O procedimento adotado foi através de questionário, o qual foi estruturado visando conhecer os seguintes focos temáticos: (1) ter conhecimento do HPV; (2) ser vacinado; (3) Saber da associação do HPV com o câncer de colo de útero; (4) Saber como é feito a imunização.

Por meio da análise e tratamento de dados, há a possibilidade de constrangimento do sujeito da pesquisa durante a aplicação do questionário. O risco de vazamento das informações também está presente, contudo, não foram utilizados aparelhos eletrônicos e 
nem imagem minimizando o risco. No momento da aplicação do questionário o entrevistado será levado para uma sala separada para que o mesmo possa se sentir mais à vontade. Todas as informações serão tratadas com maior rigor e sigilo ético, não havendo de forma alguma identificação do aluno no resultado da pesquisa não expondo o mesmo a qualquer tipo de constrangimento, atendendo a portaria 466/2012.

\section{RESULTADOS}

Dentre os alunos de ambos os sexos $76 \%$ afirmaram ter conhecimento de que a contra o HPV previne o surgimento de neoplasias, 8\% afirmaram não ter relação e 16\% não souberam informar. Observe figura 1.

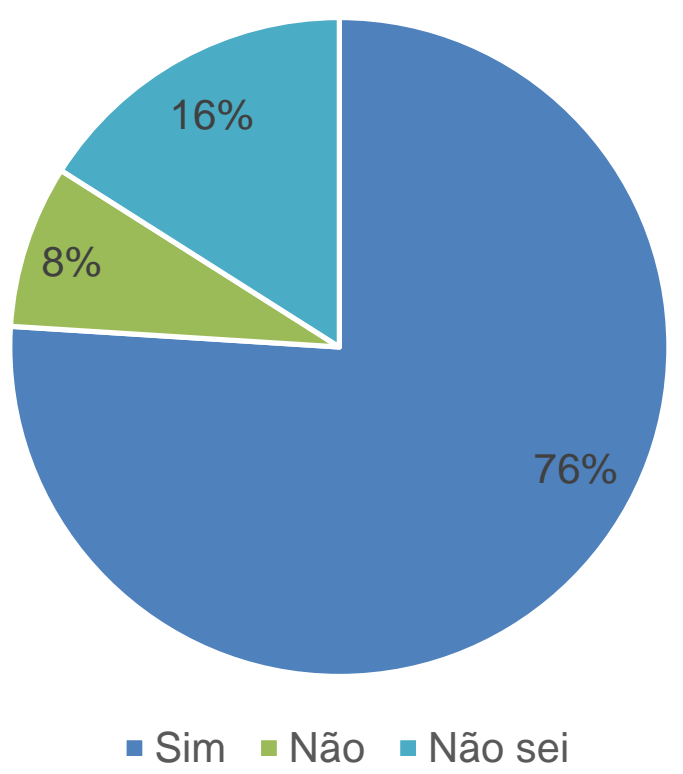

Figura 1. A vacina do HPV pode prevenir o surgimento de câncer?

Quando os alunos supracitados foram perguntados se eram vacinados contra o HPV, como pode-se observar na figura 2, 54\% afirmaram possuir imunização, $26 \%$ afirmaram que não e $20 \%$ não souberam responder. 


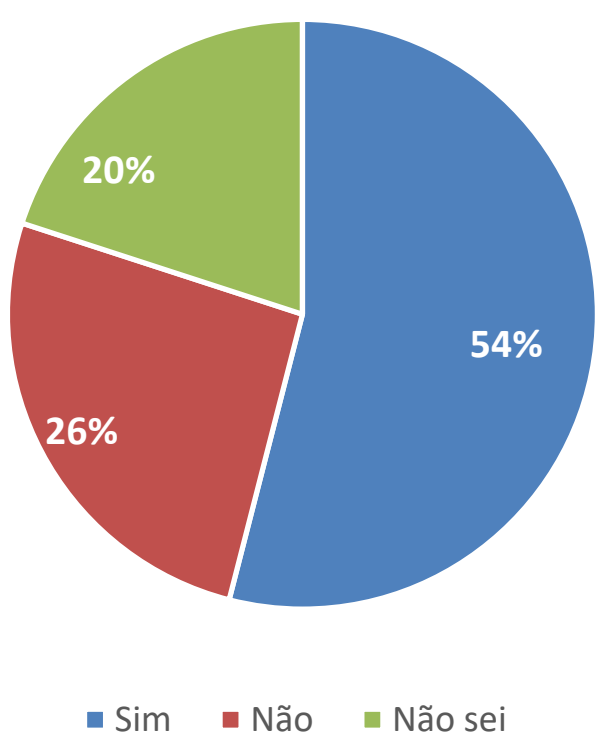

Figura 2. Você é vacinado contra o HPV?

Posteriormente a esta primeira avaliação, as variáveis foram tabuladas e avaliadas por separação de sexo, o que demonstrou números abaixo da expectativa, demonstrando a alta vulnerabilidade desta população à infecção pelo vírus HPV. Quando a variável utilizada foi questionar se a vacina do HPV poderia prevenir o câncer, $64 \%$ dos alunos do sexo masculino respondeu que sim, $12 \%$ respondeu que não, e $24 \%$ respondeu que não sabia. Observe figura 3.

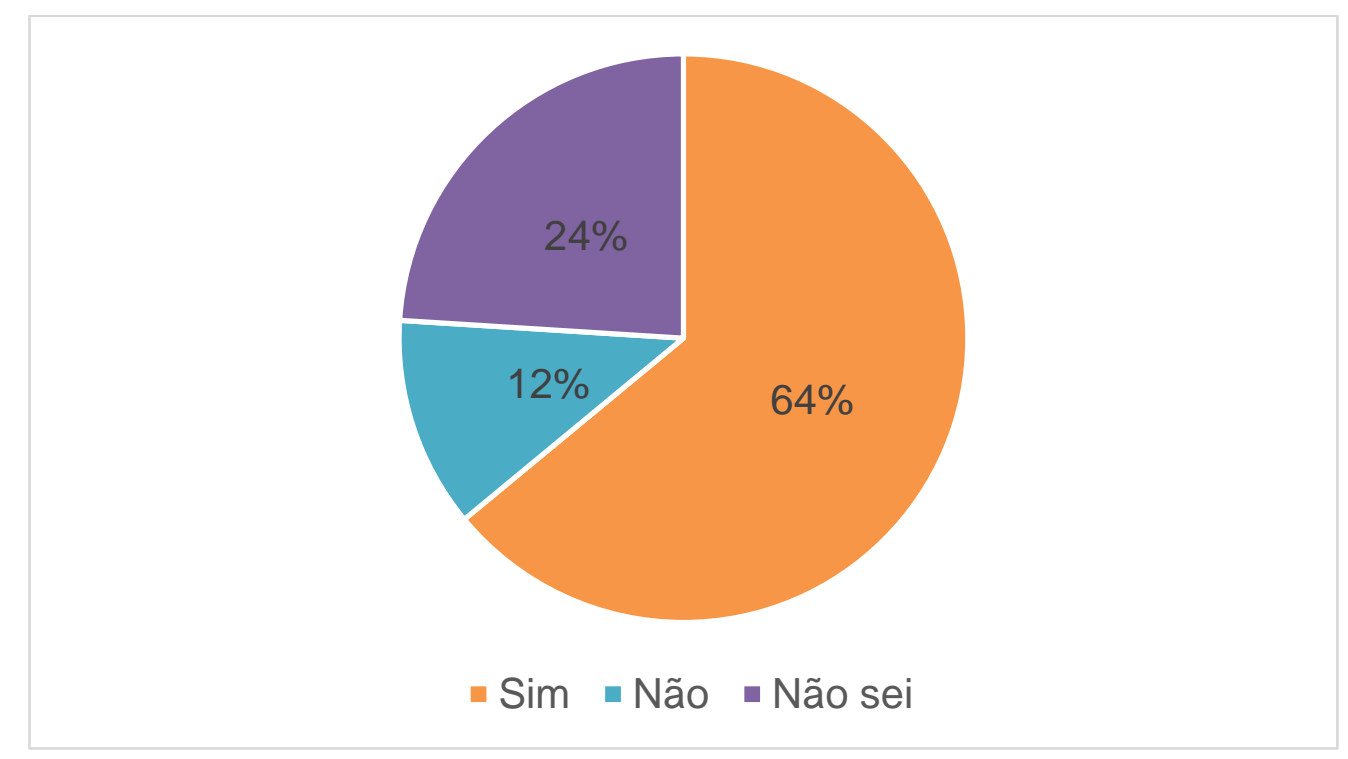

Figura 3. Sexo Masculino - A vacina do HPV pode prevenir o surgimento de câncer? 
Quando indagados se haviam sidos vacinados contra o vírus HPV, os resultados revelaram que $28 \%$ dos alunos do sexo masculino responderam que sim, $40 \%$ responderam que não e 32\% não souberam informar. Acompanhe a figura 4.

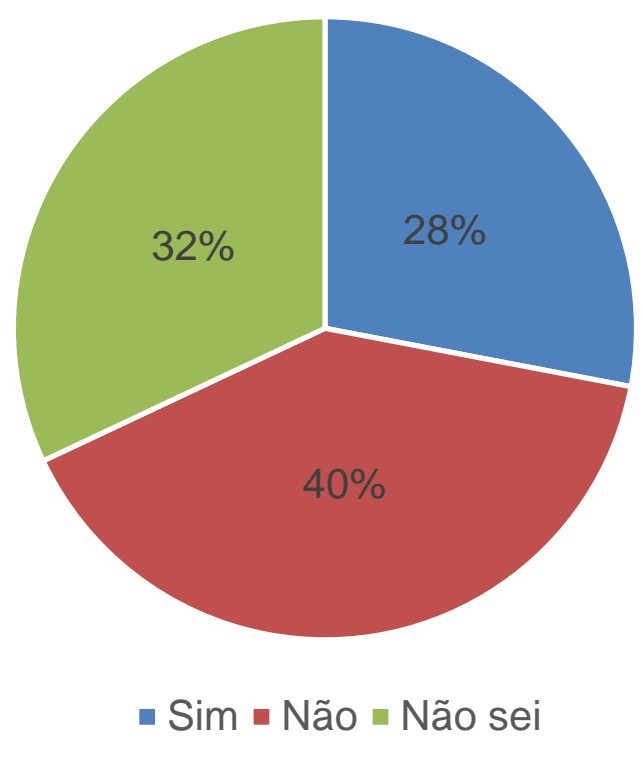

Figura 4. Sexo masculino. Você é vacinado contra o HPV?

Já as alunas do sexo feminino, quando perguntadas se a vacina do HPV preveniria o câncer. Como pode-se observar na figura 5, $88 \%$ responderam que sim, $4 \%$ que não e $2 \%$ não souberam responder.

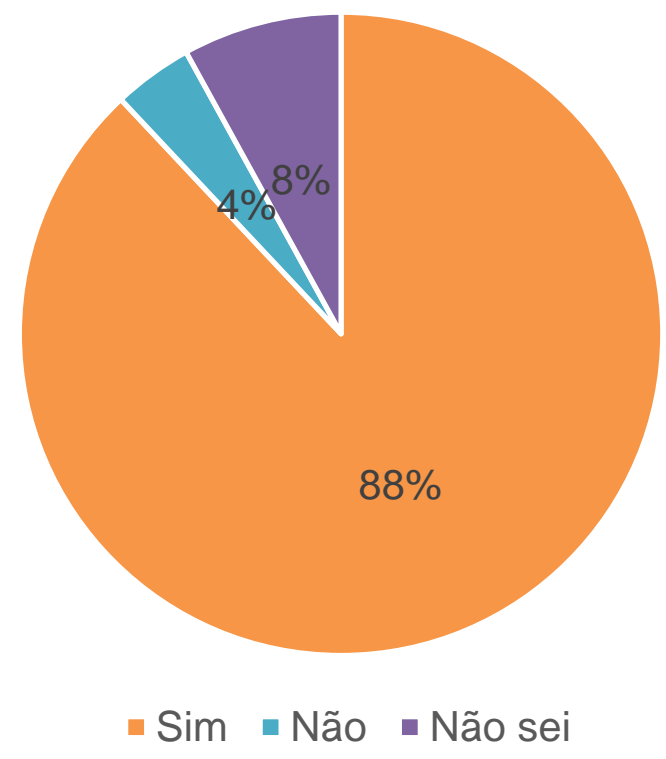

Figura 5. Sexo feminino - A vacina do HPV pode prevenir o surgimento de câncer? 
E quanto a pergunta se haviam sido vacinadas com a vacina do HPV, $80 \%$ responderam que sim, $12 \%$ que não e $8 \%$ responderam que não sabiam. Note a figura 6.

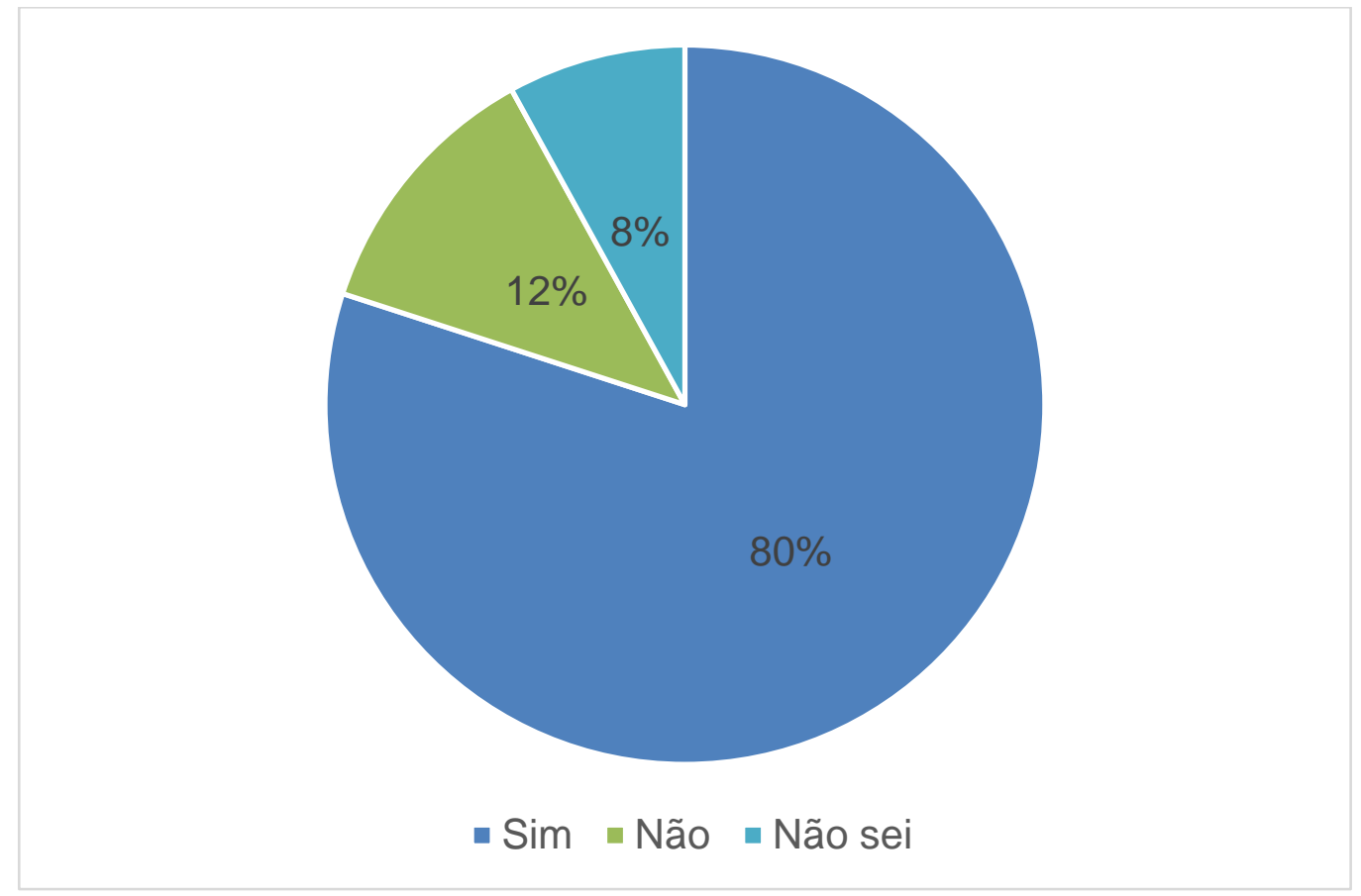

Figura 6. Sexo feminino - Você é vacinado contra o HPV?

E quanto a pergunta se haviam sido vacinadas com a vacina do HPV, $80 \%$ responderam que sim, $12 \%$ que não e $8 \%$ responderam que não sabiam.

Esses dados confirmam que o conhecimento sobre o HPV e sua associação com o câncer de colo do útero é inadequado para estudantes do ensino médio. Pode ser observado neste estudo discrepância de gênero sobre a saúde sexual. Nota-se que participantes do sexo feminino apresentavam conhecimento mais adequado sobre vacinação e complicações do papiloma vírus humano.

Esses resultados reforçam a necessidade de intervenções educativas na população para prover informação adequada sobre o HPV e sobre medidas de prevenção. Isso significa não apenas selecionar e transmitir informações cientificamente corretas sobre o HPV, mas fazê-lo de acordo com a capacidade dos diferentes estratos sociais acessarem e processarem tais informações. 


\section{DISCUSSÃO}

O adolescente no contexto da Estratégia Saúde da Família, é o público na qual se direciona o foco das campanhas de vacinação e conscientização, influenciando as decisões da atenção em saúde sobre questões pertinentes ao serviço oferecido. Deste panorama, emergem questionamentos relativos ao nível de conhecimento desses indivíduos no que tange a uma questão de saúde pública relevante e diretamente vinculada a eles e que sua adesão influencia diretamente os indicadores de saúde de cada região.

Durante pesquisa realizada OSIS (2014), que buscou analisar o conhecimento de homens e mulheres acerca do HPV e das vacinas e sua intenção de serem vacinados e de vacinarem seus filhos adolescentes. Sua pesquisa identificou que a maioria $(86,0 \%)$ dos (as) entrevistados (as) obteve escore de conhecimento acerca de DST baixo/médio (dados não apresentados em tabela). Pouco menos de $2 / 5$ dos entrevistados referiram ter ouvido falar sobre o HPV. As fontes de informações mais citadas foram: a mídia (42,0\%), escola/faculdade $(26,0 \%)$ e os serviços de saúde $(21,0 \%)$. Ginecologistas e amigos/parentes foram citados por $13,0 \%$ dos participantes.

O baixo acesso ao conhecimento sobre as prevenções do câncer de colo uterino e sexualidade no convívio familiar, principalmente em adolescentes de baixa renda, deve ser compensado pela informação na sala de aula e em campanhas de educação em saúde, utilizando-se de técnicas e linguagens apropriadas para esta população.

É senso comum que o esfregaço de Papanicolau é o exame de rastreamento e detecção precoce das neoplasias cervicais e de células precursoras do câncer de colo do útero. É possível diagnosticar lesões ainda na fase intraepitelial (não invasiva) em mulheres assintomáticas dada a lenta evolução deste câncer. Ainda se evidenciam muitos mitos, preconceitos e fantasias envolvendo a sexualidade.

De acordo com os Centros de Controle de Doenças dos Estados Unidos, 49\% das infecções pelo HPV ocorrem em pessoas entre 15 e 24 anos, com custos significativos relacionados ao tratamento. O nível socioeconômico e o grau de escolaridade baixos estão correlacionados com um prognóstico ruim em doenças relacionadas ao HPV, como a papilomatose respiratória recorrente (PRR), bem como com as baixas taxas de adesão aos programas de prevenção de infecções. No Brasil, 44,9\% da população acima de 15 anos não tem educação formal ou tem o ensino fundamental incompleto, enquanto $19 \%$ têm o ensino médio incompleto. 
A maioria dos participantes do estudo $(76 \%)$ indicou que a vacinação contra o HPV pode prevenir o surgimento de câncer, como demonstrado na figura 1. A maioria dos adolescentes responderam serem vacinados (54\%), sobretudo as do sexo feminino (80\%) já os do sexo masculino quantificados separadamente verificou- se um índice de vacinação de (40\%). Infelizmente, no sexo masculino e mesma faixa etária observamos um índice alto de não vacinados e que não sabiam informar sobre a vacinação totalizando $60 \%$ dos estudados.

De acordo com os dados do Ministério da Saúde de 2014 a 2017, 8 milhões de meninas $(79,21 \%)$ de 09 a 14 anos foram vacinadas com a primeira dose, e 4,9 milhões realizaram a segunda dose (48,7\%). Em 2017, 1,6 milhões (43,8\%) de meninos de 12 e 13 anos receberam a vacina contra HPV (BARROS, 2018).

Há um déficit importante na compreensão da importância da vacinação em ambos os sexos. Esse dado é particularmente preocupante quando se consideram as possíveis consequências de infecções persistentes nesses locais (transformação maligna) e merece atenção especial para a formulação de futuras políticas educacionais de saúde.

Os resultados indicam que a maioria dos respondentes considera estar protegidos contra a infecção pelo HPV no que tange a vacinação, no entanto muitos ainda não estão com a cobertura vacinal adequada, como notado na figura 1 , embora $76 \%$ saibam que a vacina contra o HPV pode prevenir o câncer, apenas 54\% buscaram ser efetivos nesta prevenção (figura 2).

Segundo Rotmann (2015) em seu estudo sobre a vacina contra o HPV na rede pública, a pouca aderência à vacina não é apenas no Brasil, em todo o mundo observa-se uma cobertura aquém do esperado. As mazelas presentes no país têm. Para enfrentar estes problemas, é necessário informação disseminada clara, acessível e científica para convencer a sociedade da importância desta e de outras vacinas.

Apesar que os esforços na educação em saúde tenham alcançado sucesso ao estabelecer o reconhecimento da relação entre HPV e câncer de colo do útero, esforços mais agressivos devem ser feitos para estabelecer firmemente esse mesmo reconhecimento com outros tipos de cânceres. Também é salutar a reafirmação da necessidade de vacinação dos adolescentes do sexo masculino, este resultado em consonância com estudos semelhantes confirma essa disparidade. Levando-se em consideração a potencial gravidade e os custos pecuniários relacionados com a doença associada ao HPV, o papel da prevenção é inquestionável. No entanto, para que as 
medidas de proteção individual sejam eficazes, é necessário que um nível mínimo de conhecimento sobre o assunto seja adquirido pela população.

No Brasil, destacaram-se as deficiências nos atuais programas educacionais do país sobre a infecção pelo HPV. É essencial que a política pública brasileira sobre o tema seja reavaliada. Contudo, outros autores observaram que um aumento no nível do conhecimento sobre o problema não se reflete na consciência da importância das medidas preventivas a serem adotadas. Esses autores recomendaram uma informação direta e acompanhada de argumentos que não podem ser mal interpretados.

Não há dúvida, porém, de que essa tarefa representa um grande desafio em vista das desigualdades sociais que prevalecem nesse meio, especialmente no âmbito da educação. A média de escolaridade da população brasileira não atinge sequer os oito anos do nível fundamental e existe enorme proporção de analfabetos funcionais. No âmbito do SUS, a educação em saúde é uma tarefa atribuída principalmente ao nível da atenção básica. Espera-se que se faça a promoção da saúde de acordo com o princípio da integralidade da atenção.

Por um dos pilares da concepção do SUS ser o conceito de integralidade da atenção, as ações preventivas não se desenvolvem consistentemente em todas as suas áreas de atuação. Porém, mesmo com o amplo acesso à mídia nos dias atuais, nem sempre as mensagens transmitidas são adequadas e/ou suficientes para levar as pessoas a adotarem condutas de prevenção. Isso pode ocorrer por desinformação dos próprios meios de comunicação ou por dificuldades de interpretação das pessoas que recebem as mensagens midiáticas, ou por questões culturais.

Este estudo aponta para diferenças de gênero sobre a saúde sexual. Apesar de que se tenha enfatizado a necessidade de incluir os homens nas iniciativas em saúde sexual e reprodutiva, especialmente nos últimos anos, as mulheres tendem a ser as que mais buscam informações sobre os diversos temas nessa área. Os homens culturalmente mantêm postura mais distante e resistente a comportamentos preventivos.

Em países como o Brasil, onde prevalecem relações de gênero mais tradicionais, a educação dos homens em relação aos temas inerentes à saúde sexual e reprodutiva continua a ser um desafio. Não raro, tende-se a focar as iniciativas quase que exclusivamente sobre as mulheres. Em relação à prevenção da contaminação pelo HPV, isso representa um risco para os homens, mas também, e com maior intensidade, para as mulheres. 
Embora algumas pesquisas como de Nakagawa (2010) tivessem demonstrado alta incidência de infecção pelo HPV entre adolescentes, o presente estudo demonstrou que grande parte das adolescentes não tem conhecimento adequado sobre o câncer de colo uterino e sua prevenção, dado este que traz maiores preocupações quanto à saúde sexual e reprodutiva destes adolescentes, como também questiona-se a preparação do cerne pedagógico das escolas brasileiras para lidar e preparar este público que tem uma iniciação da vida sexual cada vez mais precocemente.

No presente trabalho isto é demonstrado de forma notória, visto que $80 \%$ das alunas são vacinada contra o HPV, e apenas $40 \%$ dos alunos o são. Onde ainda, $12 \%$ das mulheres afirmam não saber sobre sua situação vacinal sobre o vírus, em comparação a $32 \%$ dos homens. O que faz perceber que grande parte dos homens sequer sabe informar sobre sua atual situação vacinal. Não obstante, apenas $64 \%$ dos alunos sabiam da relação do HPV e neoplasias, o que é alarmante por se tratar de alunos do ensino médio de um colégio conceituado em Araguaína, Tocantins.

As lacunas no conhecimento sobre a infecção pelo HPV e as suas possíveis consequências podem diminuir a eficiência e o alcance dos programas de prevenção. Embora os programas de vacinação já estejam em execução para uma grande parte da população, esses programas devem ser complementados com informações para toda a comunidade. Corroborando com a ideia de Benjamin Roitman (2015), se não for feito desta forma a eficácia dos programas de vacinação pode ser prejudicada.

\section{CONSIDERACÓES FINAIS}

A partir dos resultados obtidos neste trabalho, foi possível identificar um conhecimento superficial a respeito da temática da infecção pelo HPV em relação ao surgimento de câncer de colo do útero. Constatou-se que a maioria $(76 \%)$ da amostra conhecia a relação (sendo $88 \%$ do sexo feminino e $12 \%$ do sexo masculino). No entanto, os dados deste estudo foram obtidos a partir de um grupo que representa um nível de escolaridade acima da média no município, o que pode representar a possibilidade de serem encontrados números mais alarmantes caso a pesquisa se estendesse à outras escolas.

O fato de que a amostra desta pesquisa não foi representativa de toda a população do Brasil, bem como a limitação do recrutamento a apenas uma universidade são potenciais limitações do estudo. Entretanto, acredita-se que este trabalho possa fornecer informações úteis para políticas de orientação para a população, sobretudo a do norte do Brasil. 
É necessário que as atuais condutas públicas sobre o tema sejam reavaliadas. Isso implica trabalhar com toda a população e não apenas com as pessoas em risco de adoecer ou que estão doentes. Uma forma potencialmente eficaz de difundir educação em saúde, seria a realização de palestras sobre a temática associada a atividades dinâmicas no ambiente escolar, como forma de prender a atenção dos adolescentes, e frisar a importância de repassarem as informações em casa, para familiares e amigos. Entretanto, essa abordagem enfrenta obstáculos para se concretizar, tanto por falhas educacionais quanto pelas expectativas da população de que as unidades de saúde atuem como centros de atendimento à doença e não de prevenção.

A mídia exerce papel preponderante em comparação com a atuação dos serviços e dos profissionais de saúde como fonte de informação acerca do HPV e das vacinas, visto que grande parte da população usa a televisão e mídias sociais como principais fontes de informação e entretenimento. O SUS encontra dificuldades para cumprir sua missão quanto à educação em saúde e às ações de prevenção, como campanhas de vacinação contra o HPV e também outras.

Diante disso, é essencial promover campanhas educativas sobre os riscos de transmissão, as formas de proteção e as consequências das doenças relacionadas ao HPV para minimizar a morbidade individual e diminuir os custos para o sistema de saúde. Políticas públicas de saúde para a educação e orientação da população devem ser implantadas no Brasil de forma resoluta.

\section{REFERÉNCIAS}

ALBERTS, B. et al. Biologia molecular da célula. 6. ed. - Porto Alegre: Artmed, 2017. Cap. 23

BARROS, R.; Ministério da Saúde convoca 10 milhões de adolescentes para vacinação de HPV e meningite. 2018. Disponível em: https://www.saude.gov.br/images/pdf/2018/marco/13/CampanhaHPV-2018.pdf. Acesso em 27 set. 2020.

CASARIN, Micheli Renata; PICCOLI, Jaqueline da Costa Escobar. Educação em saúde para prevenção do câncer de colo do útero em mulheres do município de Santo Ângelo/RS. Ciência \& Saúde Coletiva, v. 16, p. 3925-3932, 2011.

COSTA, Romanniny Hévillyn Silva et al. Percepção de discentes sobre DST/HPV em uma Escola Pública no Município de Santa Cruz/RN. Revista de Biologia e Farmácia, v. 4, n. 2, 2010. 
CRUZ, Luciana Maria Britto da; LOUREIRO, Regina Pimentel. A comunicação na abordagem preventiva do câncer do colo do útero: importância das influências históricoculturais e da sexualidade feminina na adesão às campanhas. Saúde e Sociedade, v. 17, p. 120-131, 2008.

DE QUEVEDO, Josemari Poerschke et al. A política de vacinação contra o HPV no Brasil: a comunicação pública oficial e midiática face à emergência de controvérsias. Revista Tecnologia e Sociedade, v. 12, n. 24, p. 1-26, 2016.

DUARTE, Graciana Alves; OSIS, Maria José Duarte; SOUSA, Maria Helena de. Conhecimento e atitude de usuários do SUS sobre o HPV e as vacinas disponíveis no Brasil. Rev. Saúde Pública, v. 48, n. 1, fev. 2014.

INCA. COLO DO ÚTERO. Disponível em: <Http://www2.inca.gov.br/wps/wcm/connect/tiposdecancer/site/home/colo_utero/definica> Acesso em: 19 ago. 2018

NAKAGAWA, Janete TamamiTomiyoshi; SCHIRMER, Janine; BARBIERI, Márcia. Vírus HPV e câncer de colo de útero. Revista Brasileira de Enfermagem, v.63, n.2 2010.

NAUD, P. et al. Infecção pelo papiloma vírus humano (HPV). Revista HCPA, v.20, n.2, p. 138-142, ago. 2000.

NUNES, C. B. L.; ARRUDA, K. M.; PEREIRA, T. N. Apresentação da eficácia da vacina HPV distribuída pelo SUS a partir de 2014 com base nos estudos Future I, Future II, e Villa et al. Acta Biomedica Brasiliensia, v. 6, n. 1, p.1-9, 2015.

OLIVEIRA, C. M.; LEVI, J. E. HPV de Alto e Baixo Risco para Câncer: toda regra tem sua exceção. Jornal Brasileiro de Doenças Transmissíveis, Editorial. Rio de Janeiro. 2012. Disponível em:< http://www.dst.uff.br/ revista23-4-2011/2.EDITORIAL.pdf>. Acesso em: 06 set. 2020

OSIS, Maria José Duarte; DUARTE, Graciana Alves; SOUSA, Maria Helena de. Conhecimento e atitude de usuários do SUS sobre o HPV e as vacinas disponíveis no Brasil. Revista de Saúde Pública, v. 48, p. 123-133, 2014.

ROITMAN, Benjamin. HPV: uma nova vacina na rede pública. Boletim científico de Pediatria. Rio Grande do Sul, 2015. Disponível em: <https://www.sprs.com.br/sprs2013/bancoimg/150915221127bcped_v4_n1_a2.pdf>. Acesso em: 14 jan. 2020 